\title{
A Primeira Titular das Arcadas, Nair Lemos Gonçalves.
}

\author{
A Redação.
}

\begin{abstract}
Marcou a início das comemoraçōes, nesta $\mathrm{Fa}$ culdade, do sesquicentenário da Fundação dos Cursos Jurídicos no Brasil, o ato público de posse da primeira titular das Arcadas, Dra. Nair Lemos Gonçalves.

Galgando, um a um, os degraus da carreira docente, a nova titular dedicou-se intensamente à pesquisa, ao estudo de temas sociais de grande alcance $e$ a seus alunos, incentivando-os ao diálogo e à participação no trabalho de equipe.

No discurso de posse, exalta a reforma universitária que transformou as cátedras em departamentos abertos e dinâmicos; promete desenvolver o trabalho de equipe, que melhor atinge os objetivos do progresso científico, pela harmonia e capacidade dos profissionais e pesquisadores, em perfeita integração de professores e alunos.
\end{abstract}

\section{A Titular.}

Doutora Nair Lemos Gonçalves nasceu em São Paulo. É filha de Domingos Gonçalves Netto e de Dona Delminda Gomes Gonçalves.

Fez o curso ginasial e normal na Escola Normal Livre "Patrocínio de São José", em Lorena, graduando-se professora normalista em 1939.

Em 1945, fez o curso básico de Administração realizado pelo extinto Departamento do Serviço Público de São Paulo, tendo sido aprovada com média 9,18; logo em seguida, em 1946, o curso de Especialização em Organização Racional do Serviço Público, naquele Departamento, sendo igualmente aprovada.

Nesse mesmo ano de 1946, prestou concurso de provas e títulos para o cargo de Assistente do Departamento do Serviço Público, sendo aprovada em quarto lugar. Este cargo integra, hoje, a carreira de Técnico de Administração do Serviço Público Estadual. Exerceu o cargo no Instituto de Administração da Faculdade de Economia e Administração da Universidade de São Paulo no qual aposentou-se, em 1969, após 
excepcional folha de serviços, com elogios governamentais e da diretoria geral do antigo DEA.

Em 1960, habilitada pelo exercício da profissão, obteve o registro de Economista outorgado pelo Conselho Regional de Economistas de São Paulo.

Em contato com a administração de pessoal, no serviço público, que lhe exige pesquisas e estudos a respeito, interessa-se pelo Direito, ingressando na Faculdade de Direito da USP, em 1950. Conclui, pois, o Curso de Ciências Jurídicas e Sociais em 1954, ano do $4 .^{\circ}$ centenário de São Paulo.

Durante o curso jurídico, fez, ainda, em 1953, o curso de extensão universitária de Direito Penal, a cargo do Professor Dr. José Beleza dos Santos, diretor da Faculdade de Direito de Coimbra; em 1954, o de Filosofia do Direito Penal, ministrado pelo professor Dr. Luigi Bagolini, da Faculdade de Direito da Universidade de Gênova, ambos nesta Faculdade.

Foi a aluna mais premiada de sua turma; em 1952, recebeu o prêmio "Octávio Mendes Neto" pela maior média no terceiro ano; em 1953, o "Theodureto de Carvalho Filho", pela maior média no $4 .^{\circ}$ ano, e, em 1954, mais cinco láureas foram-lhe concedidas por ter alcançado a maior média geral da turma, isto é, a de 1950-1954. Foram a "Livreiro Saraiva", a do "Instituto dos Advogados", a da "Associação dos Advogados" e da "Editora Max Limonad", e, finalmente, a "Rodrigues Alves".

Em 1956, recém-formada em Direito, prestou concurso de provas e títulos para o cargo de promotor público do Estado de São Paulo, obtendo a $32 .^{\mathrm{a}}$ classificação entre 206 candidatos.

De 1956 a 1973, integra ou preside a mais de dez comissões, incumbidas de elaborar projetos para a regulamentação de serviços públicos, que na maioria foram aprovados por decretos, ou transformados em projetos de leis ou em leis, como por exemplo, o anteprojeto do quadro de servidores do Hospital das Clínicas, que foi transformado na Lei 5.392 de 26 de junho de 1959, e o anteprojeto de criação da Fundação Paulista de Promoção Social do Menor, em 1970, que se transformou na Lei $\mathrm{n}^{\circ} 185$ de 1973 . Somente em 1958, participou de seis comissões que elaboraram vários projetos aprovados por decretos, entre os quais o da Regulamentação do Pessoal do Departamento de Estradas de Rodagem; os de atualização das leis referentes ao funcionalismo público civil e da Consolidação das leis do pessoal extranumerário do Estado, todos de grande interesse e valor administrativo. 
A Primeira Titular das Arcadas, Nair Lemos Gonçalves. 
Mais tarde, em 1968, redigiu a minuta do anteprojeto de lei sobre excepcionais, elaborado a pedido da Comissão Especial da Câmara dos Deputados, incumbida de elaborar projeto de lei que atualizasse a Legislação pertinente ao Menor Excepcional. A minuta, aprovada na íntegra, pela Comissão Especial, transformou-se no projeto de Lei n. ${ }^{\circ} 1962$ de 1968.

Doutora Nair Lemos Gonçalves tem participado, também, desde 1957, de Congressos Nacionais e Internacionais, sendo relatora de temas de sua especialidade em vários deles. No primeiro Congresso Brasileiro de Medicina Física e Reabilitação e no Segundo Seminário do Instituto de Reabilitação da Universidade de São Paulo, apresentou trabalho intitulado Ingresso de Indivíduos de Capacidade Limitada no Serviço Público, Subsídios para solução do Problema - Minuta de Lei Federal.

No quinto Congresso Internacional de Direito Social, realizado em Lyon, na França, em setembro de 1963, foi relatora do Tema III, As Relações do Empregador com a Segurança Social, por Ocasião dos Acidentes do Trabalho e das Doenças Profissionais. No primeiro Congresso Brasileiro de Educação de Deficientes Visuais, foi relatora do tema oficial e assessora da Comissão Executiva.

Em 1965, participou da XIII Semana Nacional de Prevenção de Acidentes, promovida em Campinas pelo Centro de Estudos Superiores de Segurança Industrial (CESSI). Nesse Congresso apresentou trabalho sobre Legislação de Acidentes do Trabalho. Além de outros, participou, em 1968, do Congresso Internacional de Direito do Trabalho, realizado em Florianópolis, tendo apresentado contribuição publicada nos respectivos anais. Foi, ainda, membro da Comissão de Redação das Conclusões do Simpósio de Educação Especial, realizado sob o patrocínio do Ministério da Educação Especial, na Universidade de Brasília, em setembro de 1963.

\section{A Carreira Docente.}

Doutora Nair Lemos Gonçalves galgou, um a um, os degraus da Carreira Docente, nesta Faculdade. Iniciou-a como Assistente Voluntária da Cadeira de Legislação Social, em 1954, ainda estudante, e já em 1959 era a vice-diretora do Seminário de Legislação Social, cargo que desempenhou até 1969.

Em 1961, com a tese Acidente in Itinere, submeteu-se a concurso para a Livre Docência da mesma Cadeira de Legisla- 
ção Social, e aprovada por unanimidade, obteve o título de doutor em Ciências Jurídicas e Sociais e a Livre Docência da matéria.

Como livre docente, continua suas atividades de Vice-Diretora do Seminário anexo à Cadeira.

Nesse mesmo período de 1961 a 1969 exerce a regência do curso noturno e a Assistência Docente do Curso Diurno da mesma Cadeira. Ministra aulas nos III, IV, V e vi cursos de "Inspetor de Segurança" do Instituto Brasileiro de Segurança, de 1961 a 1966.

Foi professora de contrato individual e de Contrato Coletivo de trabalho nos cursos de Orientação Sindical do Instituto Cultural do Trabalho desde sua criação até a $15 .^{\text {a }}$ turma, em 1968. Lecionou nos cursos UNITRA, Universidade para o Trabalhador, organizada pelo Professor A.F. Cesarino Júnior, hoje professor emérito da Casa. Foi vice-diretora do Curso Propedêutico do Direito Comparado do Trabalho e da Segurança Social.

Como professora universitária, fez várias conferências e aulas a convite de centros acadêmicos do interior do Estado de São Paulo e de outros. Proferiu a aula inaugural dos cursos de Aperfeiçoamento do Departamento Estadual de Administração, em 1962. Foi a conferencista da Mesa Redonda sobre Aspectos da Deficiência Mental, realizada pela Associação Paulista de Medicina, seção de Taubaté, em 1965. Debateu o tema sobre Prostituição, na Semana de Estudos, patrocinada pelo Instituto Latino-Americano de Criminologia e Serviço Social do Estado, da Secretaria da Saúde e da Assistência Social do Estado de São Paulo, em 1966. Na Faculdade de Direito de Londrina, no Paraná, fez conferência sobre a Infortunística no Brasil, a convite do Centro Acadêmico "Sete de Março", daquela Faculdade. Participou da sessão solene de abertura da III Semana Nacional da Criança Excepcional, realizada em São Paulo, em agosto de 1967 e ministrou aula sobre acidente do trabalho em Curitiba a convite do Centro Acadêmico "Hugo Simas" da Faculdade de Direito da Universidade do Paraná.

Aposentada em 1970, voltou a trabalhar na Academia, na qualidade de Professora Livre Docente, convidada pela Faculdade, por iniciativa do então Chefe do Departamento de Direito do Trabalho, o eminente Professor Emérito Dr. A. Ferreira Cesarino Júnior. 
Aprovada a recondução da ilustre professora pelo então diretor, Professor Dr. José Pinto Antunes, e pela Egrégia Congregação, assumiu, em maio de 1973, a função, expressamente mencionada no contrato então realizado, de subchefe em exercício do Departamento.

Em junho de 1974 obteve o título de professor adjunto, mediante concurso de títulos.

Finalmente, com a tese Auxílio Inatividade, baseada na Lei.$^{\circ} 6.179$ de 1974 , que concedeu novo benefício previdenciário aos maiores de 70 anos e inválidos, e notável bibliografia da qual se infere constante preocupação com a situação social dos menores excepcionais, dos deficientes físicos e anciãos, submete-se a concurso para a titularidade de Direito do Trabalho. Esta a nova denominação da cátedra de Legislação Social, vaga pela aposentadoria do professor A. F. Cesarino Júnior.

Constituíram a banca examinadora os professores Drs. Miguel Reale e Irineu Strenger, desta Faculdade. Professor Dr. Geraldo Bezerra de Menezes da Faculdade de Direito da Universidade do Rio de Janeiro, Professor Dr. Aderbal Freire da Faculdade de Direito da Universidade do Ceará e Professor Dr. Célio Goyatá da Faculdade de Direito da Universidade de Minas Gerais.

Aprovada por unanimidade, a professora Dra. Nair Lemos Gonçalves é nomeada para o cargo a 19 de maio de 1976, e toma posse oficial a 26 do mesmo mês.

\section{Bibliografia.}

A Bibliografia da professora Dr. ${ }^{a}$ Nair Lemos Gonçalves versa o Direito do Trabalho, Direito Social e Administrativo, sendo muitos trabalhos considerados clássicos, e, como tal, consultados constantemente por especialistas e alunos.

Publica-se a seguir a bibliografia referida, que constituiu parte do brilhante currículo da nova titular.

1. Conceito do Funcionário Público na Administração Paulista, in Administração Paulista, v. I, n. ${ }^{\circ}$ 1, jan./jun. 1959: 15-20.

2. Contribuição para o Estudo do Direito Comparado do Trabalho Alemão- Brasileiro na parte relativa aos Acidentes do Trabalho, Revista da Faculdade de Direito da Universidade de São Paulo, Ano LIV, F. I, 1959: 209-228.

3. A Margem do Estatuto dos Ferroviários. Em colaboração com Raul Silva Jr.; Administração Paulista, v. I, n.o 2, jul./dez., 1959: 368-383.

4. A Universidade de São Paulo deve ser uma Fundação? Administração Paulista, v. I, n. ${ }^{\circ} 2$ jan./jun. 1968: 107-118. 
5. Acidente "in itinere", Aspectos Jurídicos, Especialmente em Relação ao Mundo Ocidental. Ed. Revista dos Tribunais, São Paulo, 1960.

6. Ingresso dos Indivíduos de Capacidade Reduzida ou Limitada no Serviço Público: subsídios para solução do problema. Revista da Faculdade de Direito da Universidade de São Paulo, v. LVII, 1962: 161-178.

7. As Condições de Sanidade nas Relações entre o Funcionário e o Estado. Revista da Faculdade de Direito da Universidade de São Paulo, v. LVII, 1962: 218-229.

8. Acidente "in itinere". Folha de São Paulo, 9-4-1963.

9. A Previdência Social e a Reabilitação dos Deficientes Mentais. O Estado de São Paulo, 10-5-1964.

10. As Relações do Empregador com a Segurança Social por Ocasião dos Acidentes do Trabalho $e$ das Doenças Profissionais. Revista da Faculdade de Direito da Universidade de São Paulo. Ano LIX, 1964: 101-151.

11. Subsidios para Aperfeicoamento da Legislação sobre Educação e Trabalho dos Excepcionais. Legislação do Trabalho, nov./dez., 1965: 557 . Boletim n. ${ }^{\circ}$ 30, de 1965, da Sociedade Pestalozzi do Brasil: 55.

12. O Acidente do Trabalho na Reforma dos Códigos. Justitia. Ano XXVII, $3 .^{\circ}$ Trimestre de 1965, v. 50: 209.

13. Normas de Segurança e Higiene do Trabalho, Revista IDORT, jan/fev. 1966, Ano XXXV: 409-410.

14. O Excepcional e a Legislação em Vigor, Anais do I Congresso Brasileiro de Educação de Deficientes Visuais. São Paulo, 1964: 179-186.

15. A Criança Excepcional e o Direito à Educação. Mensagem da APAE, jul./set., 1968: 28-30.

16. O Excepcional $e$ o Trabalho. Mensagem da APAE. Ano V, out./dez. 1968, n. ${ }^{\circ}$ : $09-23$.

17. Três Lustros de Ensino do Direito: Um Depoimento. 1973. Ciências e Cultura, v. 25, n. ${ }^{\circ} 8$, agosto 1973: 723-728.

18. Aspectos Legais na Avaliação da Capacidade Laborativa. 1974. Revista Paulista de Medicina, v. 85, n. ${ }^{\circ}$ 5-6, maio/jun. 1975: 138-145. Revista Brasileira de Saúde Ocupacional, v. 2, n. ${ }^{\circ}$ 6, abril/junho 1974: 20-31.

19. Proteção contra Acidentes do Trabalho: Investimento e Prevenção de Marginalidade. 1975. Ciência e Cultura, v. 27, n. ${ }^{\circ}$ 6, junho 1975: 593-601.

20. Combate a Marginalização do Excepcional em Plano Nacional, 1975. Ciência e Cultura, v. 27, n. ${ }^{\circ}$, agosto 1975: 847-858.

\section{O Ato Público de Posse.}

Aos 19 de agosto de 1976, às 20,30 horas, reuniu-se a Congregação de Professores no salão nobre, para receber solenemente, no doutoral, a primeira titular das Arcadas.

O presidente da mesa, Dr. Ruy Barbosa Nogueira, diretor da Faculdade, designou os professores Drs. Miguel Reale, Ca- 
nuto Mendes de Almeida e Goffredo Telles Júnior para introduzir no recinto a nova titular.

Recebida com grande entusiasmo pela imensa platéia de alunos e amigos, que, inusitadamente, lotava o salão, foi em seguida saudada pelo professor Dr. Oscar Barreto Filho.

$O$ orador ressaltou a feliz coincidência de nos cento e cinqüenta anos de vida acadêmica, ser a professora Nair Lemos Gonçalves a primeira mulher a ascender à culminância da carreira universitária, vislumbrando-se no caso os desígnios de Deus.

Relembrou e enalteceu a carreira docente e administrativa da professora Lemos Gonçalves e sua preocupação constante com problemas humanos da velhice, da deficiência física e dos menores excepcionais, traduzindo a sensibilidade feminina para assuntos de tão grande alcance social.

Saudou, também, a primeira titular, representando o corpo discente, o aluno do quinto ano, Helio Ribeiro que falou de improviso, interpretando o carinho e a admiração dos alunos pela professora em quem sempre encontraram compreensão e amizade. Além disso a aluna Martha Magna Cardoso ofereceu à titular uma placa de prata com a seguinte inscrição:

$\grave{A}$

Dra. Nair Lemos Gonçalves

"A Mestra do Sesquicentenário"

HOMENAGEM

Dos alunos do $4 .^{\circ}$ Ano Noturno Par, São Francisco, 19 de agosto de 1976"'.

Finalmente, a nova titular profere o discurso de posse, apresentando seu plano de trabalho, e não a "profissão de fé", mais própria dos docentes em início de carreira; comprometeu-se a dinamizar as aulas com participação direta de alunos e o trabalho de equipe, em consonância à reforma universitária, e prometeu esforçar-se no sentido da integração, a mais perfeita, dos corpos docente e discente.

\section{Saudação do Professor Oscar Barreto Filho.}

No ensejo das faustas comemorações do sesquicentenário da criação dos Cursos Jurídicos no Brasil, e da fundação da 
veneranda Academia de Direito de São Paulo, reunímo-nos hoje nesta memorável solenidade para celebrar a investidura da Professora Nair Lemos Gonçalves no alto cargo de Professor Titular do Departamento de Direito do Trabalho.

Ressalte-se, desde logo, a feliz circunstância de que, nos cento e cinqüenta anos de vida da Academia, é a Professora Nair Lemos Gonçalves a primeira mulher a ascender à culminância do último grau da carreira universitária, exatamente para ensinar a matéria em cujo conteúdo se inserem as normas de tutela do trabalho.

Circunstância essa que não pode e não deve ser atribuída apenas a uma coincidência fortuita, mas na qual se podem vislumbrar os desígnios imperscrutáveis da Providência. Nada mais certo, com efeito, do que confiar à inteligência, à cultura e à sensibilidade de uma Mulher do porte da nossa homenageada a nobre tarefa de promover o ensino e a pesquisa do Direito Social, que, além do Direito do Trabalho propriamente dito, abrange ainda todo o sistema da segurança social. Assim, à sua missão nobilitante desempenhada no recesso do lar e da escola, vem agora a Mulher contribuir decisivamente para a implantação de uma ordem social mais justa e mais humana.

Feliz é o estudioso quando, na brevidade da vida, que passa tão depressa, consegue, à custa de esforço ingente, alcançar o prêmio almejado. É tão bom realizar o ideal sonhado, na precariedade das coisas humanas!

Mas o ideal confere força desmedida a quem nele crê. Como diz a poetisa Cecília MeIRelles:

\author{
"Na verdade o chão tem pedras, \\ mas o tempo vence tudo. \\ Com águas e vento quebra-as \\ em areias de veludo. ." \\ (Canção do Carreiro/Vaga Música)
}

Com dedicação e pertinácia, devotou-se a Professora Nair a polir as pedras do seu caminho, meditando sobre os problemas sociais de sua predileção, pertinentes às áreas de reabilitação profissional, acidentes do trabalho, previdência social e metodologia do ensino, a fim de dar-lhes adequada solução.

Efetuando pesquisas, elaborando trabalhos e projetos de lei, participando de inúmeras reuniões e de muitos congressos e simpósios científicos, contribuiu a Professora Nair para o encaminhamento de soluções para relevantes problemas sociais. 
Demonstrou, por exemplo, a nítida relação que existe entre o acidente do trabalho e a reabilitação profissional, porque sem esta o acidentado permanece em situação marginal relativamente ao mercado de trabalho.

O mesmo interesse humano fê-la aproveitar a oportunidade que lhe dava o regime de tempo integral para cuidar da metodologia do ensino do Direito, realizando vários tipos de experiência com a participação dos estudantes. Para tanto, sempre procurou colaborar com o Prof. CESARINo JÚNIOR em seus propósitos de renovação do ensino, no antigo Seminário de Legislação Social, e no atual Departamento de Direito do Trabalho, dirigindo esforços no sentido de conseguir a participação direta dos alunos no processo de aprendizagem.

Colaborando com os Poderes da República, contribuiu para a redação do anteprojeto da Lei Básica do Excepcional, em cumprimento ao disposto no $\S 4 .^{\circ}$ do art. 175 da Constituição Federal, além de outros trabalhos orientados no sentido da prestação de serviços à comunidade, que constitui um dos objetivos da Universidade de São Paulo.

O "curriculum vitae" de nossa homenageada evidencia a extensão e profundidade dos seus conhecimentos na área das ciências humanas.

Formada professora normalista, ingressou no serviço público estadual, onde, sob a lúcida orientação do Professor JosÉ REIS, dedicou-se com afinco ao estudo da Ciência da Administração, no campo específico da administração de pessoal. Exerceu com proficiência inconteste o cargo de Técnico de Administração, do Instituto de Administração, da Faculdade de Economia e Administração da USP, no qual se aposentou com brilhante folha de serviços.

Foi, talvez, no exercício da função pública, que sentiu a motivação pelo estudo das ciências jurídicas. Ingressando na Faculdade de Direito de São Paulo em 1950, bacharelou-se em 1954, com as melhores notas da turma do IV Centenário.

As pesquisas e trabalhos na administração do pessoal conduziram, naturalmente, a Professora NAIR LEMos GoNÇALVES a interessar-se pelas questões jurídicas relacionadas com o trabalho humano. Já no $3 .^{\circ}$ ano do curso acadêmico, ao estudar o Direito Social, nas aulas ministradas pelo Mestre de todos nós, o eminente Professor ANTônio FERreira CESARINo JúNIOR, pôde a Professora Nair avaliar a complexidade não só das questões jurídico-legais que interferem com as relações do 
trabalho, como também dos problemas econômico-sociais e até dos verdadeiros dramas pessoais e familiares que afligem $o$ trabalhador.

Dotada de inteligência e sensibilidade invulgares para 0 estudo dos temas sociais, preocupou-se a Professora Nair em prestar sua colaboração pessoal para o estudo aprofundado do Direito do Trabalho. Após seu noviciado como Assistente Voluntária, em 1961 obtém a livre-docência da cadeira de Legislação Social, continuando no exercício de funções docentes nesta Faculdade, com o respeito e a amizade dos alunos, até fins de 1969.

Retornando ao exercício do magistério em maio de 1973, concorreu à função de Professor Adjunto do Departamento de Direito do Trabalho, no qual foi provida em 1974.

Finalmente, estamos hoje aqui reunidos para celebrar, com indizível júbilo e satisfação, a justa investidura da Professora Doutora NAIR Lemos GoNÇALvES como Professor Titular do Departamento de Direito do Trabalho, cargo no qual sucede ao ilustre Professor CESARINo JÚNIOR.

No âmbito científico, tem a Professora Nair participado de numerosos conclaves nacionais e também internacionais, entre eles o V Congresso Internacional de Direito Social, realizado em Lyon França (1963), no qual foi relatora do tema atinente aos acidentes do trabalho. Integra a Sociedade Internacional de Direito do Trabalho e da Segurança Social, o Instituto dos Advogados de São Paulo e o Instituto de Direito Social.

Além dos numerosos trabalhos publicados nas revistas especializadas sobre temas de Direito do Trabalho e de Direito Administrativo, é a autora das teses de concurso: - Acidente "in itinere - Aspectos jurídicos, especialmente em relação ao mundo ocidental" (1960); Auxílio-Natalidade - (1975), as quais demonstram o seu pendor para o trato da matéria previdenciária.

NAIR LEMOS GoNÇALVES é pesquisadora por temperamento e professora por vocação. Tenho a certeza de que nunca se sentiria feliz longe de sua amada Faculdade e dos seus diletos alunos.

Prova disso é que, afastando-se por alguns anos do exercício de suas funções docentes, quando convidada a reassumi-las, alegremente aquiesceu e retornou ao convívio dos estudantes, que tanto a prezam e admiram. 
Professora nata, depressa olvida as fadigas e os cuidados inerentes à sua missão, para lembrar-se apenas das alegrias que propicia a docência. Aluna, ontem, mestra hoje, continua estudante por todo o sempre, mantendo nos lábios o sorriso tranqüilo de quem encontrou na vida o seu ideal. Pode, como a poetisa, declamar o poema infinito do seu amor a Deus, à Humanidade, à Pátria, ao Direito e à Academia.

Ensinando todos os dias, reflete em cada aluno a pureza da sua alma, como que a dizer-nos a todo instante:

"Conservo-te o meu sorriso para, quando me encontrares, veres que ainda tenho uns ares de aluna do paraíso..."

(Cecília Meirelles/Vaga Música).

\section{Discurso de Posse da Primeira Titular.}

Agradeço ao eminente Prof. Dr. OsCar BarReto Filho haver consentido em apresentar-me oficialmente neste momento em que, com o maior orgulho, passo a integrar a E. Congregação da Academia do Largo de São Francisco, no ano de comemoração do seu Sesqüicentenário.

Dizer de seu valor pessoal e intelectual, para que se possa aquilatar a grande honra que Sua Excelência me concedeu é inteiramente desnecessário nesta Casa que tão bem o conhece.

Será, entretanto, útil relatar episódio colhido na minha longa experiência de serviço público.

Talvez não saiba o Prof. Oscar Barreto que aprendi a admirá-lo muito antes de conhecê-lo pessoalmente. Pude ver e participar do empenho com que seus pareceres eram procurados nos arquivos pelos advogados que passaram, depois dele, pelas Consultorias Jurídicas a que pertenceu, empenho motivado não só pelas sábias lições que continham os pareceres, mas também pelo que refletiam do carinho por Sua Excelência posto nos problemas que estudava e nos aspectos humanos que nunca esquecia. Esse carinho é o tempero necessário do saber, que só merece esse nome quando se sabe com amor e dedicação.

Muito obrigada Professor Oscar Barreto Filho.

Minha sincera homenagem ao eminente Prof. Dr. Antonio Ferreira Cesarino Júnior, a cujo grupo de trabalho per- 
tenci desde 1954 e a quem muito deve o Direito do Trabalho e da Segurança Social no Brasil.

A posse de hoje resulta, em grande parte, das oportunidades de trabalho que o Prof. CESARINo JúnIOR me ofereceu no antigo Seminário de Legislação Social, agora Departamento de Direito do Trabalho. Dispensável referir-lhe os méritos sobejamente conhecidos de todos. Sucedê-lo no cargo de Professor Titular é mais do que honra, enorme responsabilidade que não pouparei esforços para assumir.

$\mathrm{Na}$ apresentação de um dos seus livros, afirmou Evaristo de Moraes Filho ${ }^{1}$ que "A certa altura da vida, quando não se está mais de ida, e sim de volta, só um desejo deve inspirar àquele que publica alguma coisa: ser útil a quem porventura venha a lê-lo. A vaidade e o propósito de aparecer já estão adormecidos, em troca de um elevado anseio de servir e de esclarecer. Nada mais, e já é muito, porque o tempo vai murchando e ficando mais curto, para que se possa perdê-lo à-toa."

Esta observação, tão profunda quão verdadeira, reforçou minha antiga conviç̧ão de que, à parte o propósito de servir e ser útil, pouco resta de maior importância ao professor sujeito ao regime de tempo integral, que tenho a honra de ter sido durante toda minha vida profissional nesta Academia. Sob pena de não bem cumprir o primeiro de seus deveres, tal propósito deve inspirar-lhe toda a atividade, mesmo na época da vida em que ainda não estão adormecidos "a vaidade e o propósito de aparecer".

A vida do professor em tempo integral, afirmei em outra ocasião ${ }^{2 a}$, é obscura, aparentemente, p.ois pouco permite além de estudar e pesquisar, ocupada nesse viver continuado entre os estudantes, nesse encantamento de despertar criatividades, nessa renúncia, muitas vezes, a alardear suas próprias descobertas, para que eles possam desenvolver as suas. $\mathbf{E}$ vida de muito amor, na qual temos de apagar-nos. E nesse apagamento descobrir que, na realidade, a vida só é obscuridade quando

1. MoRaes Filho, Evaristo De, 1971, Estudos de Direito do Trabalho. LTr. Ed. Ltda., p. 15.

2. a) Gonghaves, Nair Lemos, 1973. Três lustros de ensino do Direito: um depoimento. Ciência e Cultura v. 25(8): 725 .

b) Novo benefício da previdência social: Auxilio-inatividade. 1976. IBRASA, S. Paulo.

c) Combate à marginalizagãa do excepcional em plano nacional. 1975. Ciência e Cultura, v. 27(8): 847-858. 
não há ânimo, e "o ânimo é cego se não há saber, e o saber é vão se não há trabalho, e o trabalho é vazio se não há amor", na palavra de GiBRAN ${ }^{3}$, para quem só o trabalho com amor nos liga a nós mesmos, aos outros e a Deus.

Que se espera de um novel Professor Titular na tradicional sessão pública de sua apresentação à E. Congregação desta Casa?

Diria que a resposta depende muito das condições pessoais de cada professor. Se praticamente no início de sua carreira, justo será aguardar uma "profissão de fé". Se, como eu, bem longe daquele começo, mais lógico parece que se queira ouvir uma prestação de contas, acompanhada do resumo de seu plano de trabalho futuro.

Será necessária a primeira?

Não terá sido avaliada suficientemente minha atividade pelas dignas Comissões que me examinaram nos concursos à livre-docência, à investidura no cargo de Professor Adjunto e ao provimento no elevado cargo de Professor Titular?

Não terá constituído aprovação de contas o momento em que, aposentada, recebi de minha Faculdade, em 1973, o convite para assumir a chefia do Departamento de Direito do Trabalho, em tudo que se referisse ao Curso de Graduação?

Retornando a esta Casa vi aprovadas pela E. Congregação as propostas do Conselho do Departamento de Direito do Trabalho de que resultaram a atual organização do Ciclo de Especialização, na Área do Direito do Trabalho (início em 1974) e a dos Cursos de Pós-Graduação em nível de Doutorado na mesma Área (início em 1974).

Descabido não me parece relembrar que o Conselho, ao propor a organização do ensino, partiu de três pressupostos:

$1^{\circ}$ ) Conveniência de ministrar a todos os alunos do Curso de Graduação, no $3 .^{\circ}$ ano do currículo, noções básicas teóricas e práticas de Direito do Trabalho e da Segurança Social, a fim de que pudessem iniciar atividades no setor trabalhista já mesmo no $4 .^{\circ}$ ano do curso e ainda que não viessem a optar, no $5 .^{\circ}$ ano, pela Área $\mathrm{V}$, que corresponde a essa especialidade.

Com tal propósito distribuiu os assuntos pelas duas disciplinas intituladas DIREITO DO TRABALHO, incluindo na primeira

3. Gibran, Kahlil. 1955. The Prophet. Knopf, Nova York, p. 26. 
questões de Direito Individual do Trabalho e Direito da Segurança Social, do qual a premência de tempo só permite cuidar de aspectos de previdência social, e, na segunda, questões de Direito Processual do Trabalho e Direito Coletivo do Trabalho.

Assim entendeu tendo em vista a freqüência com que se apresentam, na prática, questões trabalhistas e de previdência social.

2. ${ }^{\circ}$ Conveniência da complementação das noções básicas, com aprofundamento teórico-prático no $5 .^{\circ}$ ano, onde, para efeito didático, o estudo se distribui em 8 (oito) disciplinas: Direito Individual do Trabalho I e II; Direito da Segurança Social I e II; Direito Coletivo do Trabalho I e II e Direito Processual do Trabalho I e II.

$3 .^{\circ}$ ) Conveniência de, sempre que possível, dar às disciplinas de pós-graduação em Direito do Trabalho e da Segurança Social caráter monográfico, para permitir o aperfeiçoamento científico indispensável aos candidatos potenciais à carreira docente ou a de pesquisador de nível superior, que os Cursos de Pós-Graduação objetivam formar. O caráter monográfico já é realidade nas disciplinas intituladas Direito Protecionista Comparado do Trabalho e, com o futuro melhoramento da organização do ensino, deverá abranger as outras disciplinas.

Esta a organização atualmente implantada, cuja referência me pareceu indispensável para melhor entendimento do plano de trabalho futuro.

É óbvio que a eficiência dessa organização se baseia principalmente no corpo docente incumbido da execução das tarefas.

Inegável também a interligação, no âmbito da Universidade, do progresso da ciência jurídica (como as demais) com as oportunidades de debates que permitam trocas de idéias dos docentes entre si e com o corpo discente. A tônica da reforma universitária, segundo os especialistas que dela participaram, parece ter sido, aliás, principalmente a substituição da influência individualista dos professores das antigas Cátedras pela de equipe, representada nos Conselhos Departamentais, considerado o Departamento a "menor fração da estrutura universitária" incumbida da "responsabilidade da elaboração e do desenvolvimento de programas delimitados de ensino, pesquisa e extensão de serviços à comunidade, intimamente correlacionados, de conteúdo homogêneo, e unificado, que se utilizem de recursos comuns de trabalho" (Estatuto da Universidade de São Paulo, art. 45 e $\S 1 .^{\circ}$, grifo meu). 
Ora, trabalho de equipe exige conjunto harmonioso de pessoas e, num Departamento universitário, sempre que possível, conjunto dos melhores profissionais existentes em cada área. Porque Departamento fechado nada mais será do que feudo e pouco se diferenciará da Cátedra antiga, proscrita pela Reforma.

É claro que sempre houve e haverá, para honra do corpo docente de todas as épocas e lugares, especialmente nesta Academia, para felicidade nossa, verdadeiros professores, a quem o saber jurídico atual e futuro muito deve, que transformavam suas cátedras em escolas autênticas, às quais muito dificilmente poderão comparar-se, em eficiência, alguns Departamentos de hoje.

É mais um exemplo de que o importante é o Homem e não a denominação adotada para as coisas e instituições.

Como plano de trabalho principal, cuja execução não dispensará a preciosa colaboração dos meus eminentes colegas, integrantes desta E. Congregação, apresento a ampliação do Departamento de Direito do Trabalho, cujos docentes estão com excessivas cargas horárias de trabalho.

Com grande interesse aguardo a próxima realização dos concursos para provimento dos dois cargos vagos de Professor Adjunto, habilitação à livre-docência em Direito do Trabalho e ingresso na carreira docente. Candidatos não faltarão em qualquer dessas hipóteses, porque além dos profissionais já integrantes do corpo docente desta Faculdade, os Cursos de Pós-Graduação já revelaram na área do Direito do Trabalho excelentes profissionais e estudiosos.

Beneficiar-se-á também o Departamento de Direito do Trabalho com a realização oportuna do concurso para provimento do cargo de Professor Titular, vago com a aposentadaria do Prof. Dr. Antônio Ferreira Cesarino Júnior em 16 de março de 1976.

Não posso silenciar minha satisfação por terem ingressado no Departamento de Direito do Trabalho, a partir de 1974, grandes especialistas como os Srs. Profs. Drs. Amauri Mascaro Nascimento, Wagner D. Giglio e Cássio de Mesquita Barros Júnior, que enriqueceram o corpo docente e garantiram a abertura do Departamento, que sempre desejei.

Praza a Deus se aperfeiçoe o Departamento, transformando-se em "verdadeira e sólida equipe", porque assim estará 
mais próximo do ideal que a reforma universitária pretendeu alcançar ao substituir Cátedras por Departamentos.

Realizada a parte do plano de trabalho futuro referente ao corpo docente alcançará também o objetivo do corpo discente, porque mais intenso será o diálogo entre professor e aluno.

Já existem aulas programadas com a colaboração discente, cuja eficiência vem sendo todavia perturbada pelo acúmulo de tarefas docentes e pela escassez do tempo disponível dos alunos, que na maioria trabalham para custear a própria subsistência.

Na chefia do Departamento procurarei dinamizar essa espécie de atividade, que considero da mais alta importância no processo da aprendizagem, porque coloca o professor na função que me parece principal de agir como catalizador, procurando levar o aluno a desenvolver-se ativamente.

A reforma universitária deu ao corpo docente auxiliares de grande valor. Refiro-me aos representantes discentes que integram os diversos órgãos colegiados, cuja ação tem facilitado grandemente o diálogo desejado. Há ainda os representantes de classe, eleitos ou escolhidos espontâneamente de cuja eficiência dou testemunho.

Em resumo, meu plano de trabalho futuro será, como Chefe do Departamento e com a colaboração dos eminentes colegas, solidificar a equipe do Direito do Trabalho e da Segurança Social formada pelos corpos docente e discente.

Impossível fora encerrar minhas palavras sem dirigir-me especialmente aos alunos atuais e futuros, procurando deixar-lhes pensamento digno de reflexão.

Meus prezados alunos atuais e futuros desta Faculdade e da Faculdade de Economia e Administração, que também foi minha Casa em 1946 e a qual retorno feliz 30 anos depois.

Ao lado de uma ordem pública econômica pode-se distinguir uma ordem pública social com o fim de assegurar relações sociais mais eqüitativas, pela proteção de categorias de cidadãos que, em virtude da força econômica de outras categorias com as quais estão em constante antag.onismo, sem ela veriam limitadas sua liberdade e dignidade e impedida a realização da própria personalidade.

Tão velho talvez como a humanidade, repetido insistentemente, de vários modos, pelos filósofos do Direito e especialmente pelos juslaboristas, apresento aos meus alunos um pen- 
samento básico, valendo-me de expressões, quase literais, de RENATO CORRADO ${ }^{4}$ porque nelas acho os elementos principais a considerar no momento em que vivemos: liberdade, dignidade e personalidade.

Nos congressos e reuniões internacionais já se vai reconhecendo que o objetivo direto de natureza econômica, embora de importância inegável, não é o único nem o principal a que visa o Homem. Só a valorização da pessoa humana e o reconhecimento a todos do direito ao desenvolvimento pleno de suas aptidões e ao acesso às oportunidades que a vida oferece podem colocar o ser humano na verdadeira posição que lhe compete em qualquer comunidade, afastando-o de condições de existência que praticamente o equiparem ao animal irracional.

$\mathrm{Na}$ tese cuja aprovação me trouxe a esta elevada tribuna (2b), procurei reunir dados que confirmam esta afirmação, dentre os quais a Convenção n. ${ }^{\circ} 117$, aprovada em 1962, pela Conferência Internacional do Trabalho, que inclui, como princípio de política social, entre outros, o de que o "melhoramento do nível de vida deverá ser considerado como objetivo principal dos planos de desenvolvimento econômico."

Oportuno é lembrar alguns exemplos de categorias que não dispensam proteção especial.

Surgidos com a primeira Revolução Industrial, os assalariados parecem a categoria única referida por RENATO CORRADo, porque pelas suas condições de trabalho, que exigiam a reunião de numerosos trabalhadores nas fábricas, foi a primeira a transformar-se em grupo de pressão cuja força obrigasse o Estado a intervir na ordem econômica, a fim de equilibrar "com certa superioridade jurídica a inferioridade econômica" em que se encontrava o Trabalho relativamente ao Capital, expressões nunca demais repetidas de GALLART FOLCH ${ }^{5}$.

Hoje, o conjunto de normas que os especialistas alemães adequadamente denominam de "protecionistas" (limitação da jornada do trabalho, repouso remunerado semanal e anual etc.) permeia o Direito de todos os países, inclusive os sujeitos ao regime socialista, onde também é grande o interesse na manutenção da capacidade laborativa dos seres humanos, cujo

4. Corrado, Renato. 1965. Trattato di Diritto del Lavoro. Ed. UTET, Turim, v. II, p. 716.

5. Gallart Folch, Alejandro. 1936. Derecho Español del Trabajo, Ed. Labor, p. 16. 
exercício eficiente constitui a maior riqueza de todas as Nações. Em países como o nosso, da chamada economia de mercado, tais normas criam direitos e deveres para empregados e empregadores e, nesta Faculdade, fazem parte dos programas de Direito Individual do Trabalho.

Esta proteção exige entre nós e nos países ocidentais, como regra geral, a prévia existência de um contrato individual de trabalho ou, para alguns, da relação de emprego, isto é, não dispensa a prestação de trabalho subordinado a empregador. O assalariado é protegido por normas dessa natureza quando e enquanto trabalha.

Mas a organização do trabalho não é uniforme e, por isso, outros cidadãos, tendo a mesma necessidade de proteção, não podem manter relação de emprego diretamente com as organizações que lhes utilizam a capacidade laborativa, exercida de forma subordinada, porque a natureza das tarefas que lhes são próprias os faz trabalhar ao mesmo tempo, às vezes num só dia, para diversas empresas. O exemplo mais simples é o dos trabalhadores da zona portuária (estivadores, carregadores etc.), cuja proteção exige a intermediação do sindicato da categoria, que recebe as empresas o numerário correspondente aos "encargos sociais", fazendo posteriormente os pagamentos determinados pela legislação trabalhista.

São os chamados "trabalhadores avulsos", cuja situação não está ainda devidamente regulada no Brasil. Muitos dos integrantes dessa categoria não possuem ainda organização ou sistema de intermediação que lhes garanta os direitos sociais mais elementares. Os especialistas do Ministério do Trabalho e em geral os estudiosos de Direito do Trabalho, em todas as áreas, estão hoje vivamente interessados na pesquisa da solução mais conveniente para a situação precária em que se encontram cidadãos ironicamente chamados "boias frias", "pilões" ou "birolos", irmãos nossos que, de fato, são assalariados porque exercem trabalho subordinado na zona rural, mas constituem trabalhadores volantes que, pelo interesse dos empregadores rurais em potencial, precisam permanecer executando o mesmo serviço ora numa fazenda ora noutra, para evitar a configuração da continuidade na prestação do trabalho, que faria surgir a relação de emprego e com ela os encargos sociais. Embora menores, já existem esses ônus patronais também na área não urbana.

Estes exemplos parecem suficientes para demonstrar o dinamismo peculiar do Direito do Trabalho, que leva muitos dou- 
trinadores a negar utilidade ao Código do Trabalho. Em recente entrevista o Ministro PUECH ${ }^{6}$, hoje na presidência da mais alta Corte Trabalhista brasileira, foi categórico ao repetir sua doutrina segundo a qual "A dinâmica das relações de trabalho impõe legislação instável e que, sob certos aspectos, constituem leis extravagantes" Considera tais leis "como imperativo da ordem econômica e social" e, embora reconhecendo as dificuldades que delas derivam, acolhe "como contingentes, como inevitáveis ou como naturais as mutações que a ordem econômica e social impõe à ordem legal e que tantas vezes inscrevem-se em leis extravagantes".

Espero que eles permitam sentir a íntima e indispensável relação entre o social e o jurídico, para que não se estranhe que dissertações e teses elaboradas no âmbito do Direito do Trabalho dêem tanto realce a considerações de ordem social. Essa relação que em alguns campos do Direito às vezes parece esgarçar-se, assume especial relevo no Direito do Trabalho.

Também os empregadores podem constituir categoria que não dispensa a proteção da legislação trabalhista. Muitas vezes se nota nas médias e pequenas empresas debilidade econômica semelhante a do assalariado, por parte dos empresários que tiram de sua atividade na empresa os recursos necessários à subsistência própria e dos seus familiares. Cedo se verificou, notadamente nos países em desenvolvimento e, por isso mesmo, onde não raro os recursos nacionais são parcos e a economia é precária, a necessidade de estender aos empregadores a proteção das normas de previdência social destinadas de início aos assalariados. Isto porque, cessada ou diminuída a possibilidade de trabalho, pela redução ou perda da capacidade laborativa, ficavam também eles em situação de necessidade. Assim se explica o alargamento do campo de aplicação das leis de previdência social no Brasil, como em todo o mundo, em busca de sistemas ideais de segurança social que libertem todos os cidadãos da necessidade, quando ela se apresente. Não estranharão, por isso, meus alunos, que o Instituto Nacional de Previdência Social se incumba de conceder benefícios aos donos de empresa. Se há antagonismo entre Capital e Trabalho, no campo do Direito Individual do Trabalho, verão que a grande solidariedade, indispensável ao bem-estar geral, é elemento que reúne todos os cidadãos quando se trata de relações jurídicas

6. Puech, Luiz Roberto de Rezende. Entrevista. Revista de Direito do Trabalho. 1976. Ano I, (1): 13-16. Ed. Rev. Trib. S. Paulo. 
objeto de estudo do Direito da Segurança Social. Não pode haver antagonismo quando se trata de defender o Homem contra a necessidade e a miséria.

A categoria dos excepcionais compreende variedade enorme de situações, que exigem normas adequadas, não só no campo do Direito do Trabalho e da Segurança Social, como praticamente em todos os ramos do Direito, porque a falta dessas normas levaria cidadãos, como de fato tem levado, à marginalização condenada em todo o Universo.

Lembremos a Constituição Federal, na redação que lhe deu a Emenda Constitucional n. ${ }^{\circ}$ 1, de 1969: "Lei especial disporá sobre a assistência à maternidade, à infância e à adolescência e sobre a educação dos excepcionais." (Art. $175 \S 4 .^{\circ}$ ) e a Constituição do nosso Estado quando determina que "O Plano Estadual incluirá a educação dos excepcionais do físico, dos sentidos e da inteligência." (Art. 126 § 2..$^{\circ}$ ).

Quem é o "excepcional" destinatário das normas constitucionais?

Assunto de minha predileção, pelo profundo caráter humanitário de que se reveste, tive oportunidade de elaborar, a pedido da Câmara dos Deputados, em 1968, anteprojeto de lei cujo objetivo era estabelecer normas adequadas para atender aos diversos problemas da vida dos excepcionais.

Quando surgiu entre nós, com maior publicidade e divulgação, a palavra "excepcional" era sinônimo de pessoa com deficiência mental e visava ao afastamento de expressões condenáveis, porque traziam o perigo de estigmatizar seres humanos tão dignos de consideração como outros quaisquer. Refiro-me a "débeis mentais", "idiotas", ou mesmo, por incompreensão, "loucos", categoria em que se classificavam os excepcionais, e lamentavelmente continuarão a classificar-se, enquanto não alterada a redação do Código Civil, pela falta de outra mais adequada, quando se cuida da negação de sua capacidade civil (art. 5. ${ }^{\circ}$.

Na interpretação da Lei Magna não se poderá admitir significação tão restrita. Se considerarmos que a palavra aparece nas Constituições de praticamente todos os Estados brasileiros (Acre, Alagoas, Amazonas, Bahia, Ceará, Espírito Santo, Maranhão, Mato Grosso, Minas Gerais, Paraíba, Rio Grande do Sul, Rio de Janeiro, Santa Catarina, São Paulo e Sergipe), sempre para assegurar aos excepcionais proteção especial, cresce de importância o sentido a ser atribuído ao vocábulo. 
Eminentes constitucionalistas não estão de acordo quanto ao alcance da inovação da Emenda Constitucional n. ${ }^{\circ} 1$, contida no art. $175 \& 4 .^{\circ}$. Segundo PoNTES DE MIRANDA ${ }^{7}$ "Excepcionais" está, aí, por pessoas que, por faltas ou defeitos físicos ou psíquicos, ou por procedência anormal (nascido, por exemplo, em meio social perigoso), precisam de assistência." MANOEL GONÇALVES FERREIRA FILHO ${ }^{8}$ admite sejam considerados excepcionais" aqueles que por motivos físicos ou psíquicos se encontram em situação de inferioridade em relação aos chamados normais", porém considera a interpretação de PONTES DE MIRANDA "excessiva e ademais inútil" quando vai além incluindo "aqueles que nasceram em meio perigoso", porque "a proteção à infância e à adolescência há de levar em conta a proveniência dos que devem ser protegidos. Nisto já se antevê ou se antecipa a previsão de normas especiais para os provenientes dos chamados meios perigosos."

Não é fácil a solução do problema. Pontes DE MIRANDA ao dar a amplitude condenada por MANOEL GONÇALVES FERREIRA FilHo talvez tivesse em mente pessoas que apresentam os chamados "desvios de conduta", as quais Helena ANTIPofF, pioneira na educação de excepcionais sempre reconheceu mais necessitadas de proteção especial e que, juntamente com outros excepcionais, teve em vista ao organizar o excelente trabalho da conhecida Fazenda do Rosário.

Vê-se que ambos são concordes em colocar o "excepcional" apenas na faixa das pessoas infradotadas.

Considerando a contribuição doutrinária brasileira e estrangeira, afirmei, em 1968 ao redigir o anteprojeto de lei oferecido à Câmara dos Deputados e mais recentemente em outro trabalho (2c) que a palavra excepcional deveria abranger igualmente pessoas que se situem aquém (infradotados, minusválidos) ou além (superdotados) dos limites mínimos e máximo próprios dos padrões médios comumente observados na avaliação das aptidões e capacidades dos seres humanos, porque, afastando-se desses limites, constituem exceções à regra geral. Apresentei como requisitos principais e concomitantes na definição de "excepcional" o desvio acentuado dos mencionados padrões médios e sua relação com o desenvolvimento físico,

7. Pontes DE Miranda. 1972. Comentários à Constituição de 1967 com a Emenda Constitucional n. ${ }^{\circ}$ 1, de 1969 , v. VI, p. 333, Ed. Rev. Trib.

8. Gonchalves Ferreira Filho, Manoel. 1975. Comentários à. Constitui६̧ão Brasileira. Ed. Saraiva, v. $3 .^{\circ}$, p. 217. 
mental, sensorial ou emocional, considerados esses aspectos do desenvolvimento separada, combinada ou globalmente.

Acentuado é o desvio que exige processos de educação especial e reabilitação, ou o reconhecimento de situação jurídica especial que permita a integração social da pessoa, com iguais oportunidades na vida, ou, em outras palavras, a subtração dessa pessoa à marginalização em que se encontra.

Reconhecendo a dificuldade da definição, admiti caber aos técnicos decidir sobre se a melhor orientação deverá ser a definição legal do excepcional, ou a indicação na Lei Básica dos requisitos julgados principais, deixando ao decreto a definição, para maior facilidade de aperfeiçoamento futuro exigido por eventuais dificuldades que a execução da lei possa acarretar.

Será conveniente incluir desde logo os desvios de conduta entre os requisitos alternativos que o destinatário da norma deverá preencher? Dada a dificuldade de diagnóstico e conceituação desses desvios, não será mais prudente deixar para inclui-los após algum tempo de execução da Lei Básica?

Para atingir plenamente a integração do excepcional, as normas de proteção devem abranger todas as fases de sua vida (infância, juventude, maturidade e velhice), assegurando não só a coordenação dos esforços próprios de cada uma delas, mas também desses esforços entre si, num processo contínuo que propicie à criança excepcional, ao chegar à idade do trabalho, preparo profissional que lhe assegure oportunidades de emprego e ascensão e, na velhice ou invalidez, situação garantida pela previdência social, bem como amparo de sua família, no caso de morte.

A mais este exemplo de categoria que não dispensa a proteção referida por RENATO CORRADO, falta acrescentar apenas que os cidadãos podem dela fazer parte a partir do nascimento, ou nela ingressar depois, em qualquer fase da vida, quando a deficiência se apresente. Não esqueçamos o acidentado do trabalho a quem a redução da capacidade laborativa muitas vezes retira a possibilidade do exercício da profissão que desempenhava no momento do acidente, não raro a única atividade para a qual está habilitado. A solução, nessas circunstâncias, encontra-se freqüentemente em processos de reabilitação, garantida também por normas próprias do mesmo sistema de proteção.

Para bem realizada, exige a reabilitação disposições adequadas de Direito Individual do Trabalho, que afastem 
dificuldades na admissão quando a deficiência do excepcional não prejudique o rendimento satisfatório de seu trabalho, autorizem cautelosamente a alteração das tarefas a que se obrigou o empregado pelo contrato, quando a deficiência o impedir de exercê-las, e assim por diante. O Direito Coletivo de Trabalho, por seu lado, poderia prever, entre outras medidas, a estreita colaboração das entidades sindicais na atividade de fiscalização do cumprimento dos programas de reabilitação nas fases realizadas nas empresas. Ao Direito da Segurança Social caberia a responsabilidade maior de criar condições de execução dos programas de reabilitação, prevendo órgãos de execução públicos ou particulares e outros meios semelhantes. Normas adequadas de Direito Processual do Trabalho assegurariam celeridade especial nos processos referentes à execução de fases da reabilitação realizadas nas empresas, evitando, também, neste aspecto, a "tendência de solenizar a Justiça do Trabalho", como muito bem salientou o Ministro PUECH na entrevista citada, enfrentando os problemas com a "coragem de inovar", pela qual "Os moldes clássicos hão de ser relegados, substituídos, de forma a assegurar-se o objetivo da Justiça especial do Trabalho", conforme igualmente esclareceu Sua Excelência, acrescentando que "enquanto a Justiça Comum vai buscar, na do Trabalho, alguns de seus modelos revolucionários, a Justiça do Trabalho vai buscar, na Justiça Comum, algumas técnicas de marcado conservadorismo."

Enfaticamente afirmou BaLlester HoYs ${ }^{9}$ que " . . ningún pais puede hoy considerarse lo suficientemente rico para despreciar la mano de obra inválida". (No Direito brasileiro a expressão "inválida" está implícita no vocábulo "excepcional"). Diz o mesmo especialista em reabilitação que as gerações ativas hão de elevar seu nível de vida e fazer que participem de seu bem-estar os inválidos e os aposentados, as crianças e todos os que, por qualquer motivo permaneçam fora da produção; nenhum material será perdido desde que seja utilizável. E, continua, "Na mentalidade dos capatazes só há trabalho para os fortes. Nega-se um posto de trabalho aos débeis ou deficientes (Diríamos excepcionais.), ainda que existam postos de trabalho que eles possam desempenhar satisfatoriamente. Tal conduta é desumana e antieconômica".

9. Ballester Hoys, Agustín. 1966. "El trabajo protegido y la Rehabilitación de inválidos". Revista Iberoamericana de Seguridad Social. Ano XV (4): 815-834. 
Além de desumano e antieconômico existe nesses casos verdadeiro desperdício, o que torna oportuno contar a estória: "Os calhaus grandes e os seixos pequenos", contida no pioneiro livro intitulado Previdência, escrito em 1913 por OTHELO DE SOUZA REIS ${ }^{10}$ : Um homem "vivia a se lamentar da sua má fortuna: não tinha nada de seu, passava fome e frio." Um dia apareceu-lhe uma fada que o levou para vasto terreno que parecia "depósito de coisas inservíveis", dizendo que ali havia "uma rica mina de ouro" Os trabalhos de mineração acabaram, mas ainda se encontram em muitos desses blocos pedaços de ouro incrustados. Há ainda tanto do precioso metal, que se o apanhares cuidadosamente faiscando estes calhaus, serás mais rico do que todos os poderosos do mundo." Recomendou-lhe trabalhar, limpar o terreno e lançar num poço "O que não servir". O homem obedeceu a fada, mas "Só guardava os grandes (calhaus), que continham muito ouro. Afinal, limpou o terreno. A fada apareceu e levou o homem para o fundo do poço onde se encontrava o material por ele julgado inservível." Ali, "anõezinhos trabalhavam numa forja, outros batiam, outros limavam pedaços de ouro. De outro lado, outros arrumavam em pilhas uma porção de moedas que tiniam umas contra as outras, com o som das verdadeiras, de ouro. - Vês? disse-lhe a fada, todas estas moedas foram feitas com o ouro dos calhaus que atiraste fora. São muito mais do que as que conseguiste com os teus blocos grandes. "O homem voltou a trabalhar em outro lugar e "ganhou uma fortuna enorme."

Talvez pareça descabido lembrar a universitários este conto destinado a alunos da escola primária, mas não será verdadeira criancice do nosso País pobre andar desperdiçando tanta capacidade residual aproveitável? Posso dar testemunho de não poucas pessoas que, aprovadas em concursos públicos, foram rejeitadas no exame médico, porque apresentam deficiências físicas que de modo algum prejudicariam o pleno exercício das atribuições próprias da função para a qual mereceram aprovação.

Há ainda os trabalhadores de certa idade. O Decreto espanhol n. ${ }^{\circ} 2431$, de 1966, dispôs sobre o emprego de trabalhadores de idade madura. A justificativa que o acompanhou, referindo-se aos obstáculos ao processo de adaptação econômica

10. ReIS, Othelo de Souza. 1913. Previdência. Pap. Macedo. Rio de Janeiro. 
e social da Espanha, apontou a dificuldade desses trabalhadores em encontrar emprego, quando algumas empresas estabelecem limitações de contratação por causa da idade. Atribui o problema, em muitos casos, a preconceitos totalmente injustificados, conforme demonstrado por estudos de especialistas em âmbito nacional e internacional. Só se justificaria a preferência pelos mais jovens quando a especial natureza do trabalho exigisse condições de vigor físico, resistência funcional ou capacidade de reflexos mais comuns na idade juvenil que na maturidade 11. Motiva esta última consideração já estar a idade aparecendo no Brasil como empecilho à obtenção de emprego. Esta situação tenderá a agravar-se no futuro, porque, se a vida média do brasileiro se eleva e a nossa população é predominantemente jovem hoje, haverá nos próximos 15 ou 20 anos (se antes não tivermos encontrado a solução no sistema de proteção a que se refere RENATo CoRrado) exércitos de pessoas em idade madura e com dificuldade na obtenção de emprego. Tão grave situação vem sendo provocada também pela já excessiva rotatividade da mão-de-obra propiciada pela Lei do Fundo de Garantia do Tempo de Serviço. Pressentida pelos especialistas, que negaram à citada lei o caráter de bom substitutivo da estabilidade, essa mobilidade é agora, segundo divulga a imprensa, admitida pelos círculos oficiais, preocupados com o aperfeiçoamento das normas que regulam aquele Fundo.

Prezados alunos meus, observai, pela muita reflexão que desperta o pensamento de RENATo CoRRADo, quão imenso é o campo de estudo do Direito do Trabalho e da Segurança Social, no qual, repito, impossível será trabalho jurídico eficiente sem sólido fundamento social.

E. Congregação, eminentes colegas, senhoras e senhores, muito obrigada.

11. Revista Iberoamericana de Seguridad Social. 1966. Ano XV (5) : 1099. 